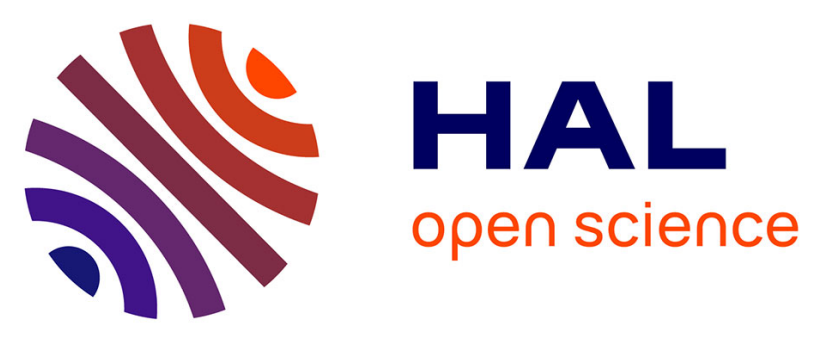

\title{
Electronic Energy Transfer Modulation in a Dynamic Foldaxane: Proof-of-Principle of a Lifetime-Based Conformation Probe
}

Sergey A. Denisov, Quan Gan, Xiang Wang, Luca Scarpantonio, Yann

Ferrand, Brice Kauffmann, Gediminas Jonusauskas, Ivan Huc, Nathan D.

Mcclenaghan

\section{To cite this version:}

Sergey A. Denisov, Quan Gan, Xiang Wang, Luca Scarpantonio, Yann Ferrand, et al.. Electronic Energy Transfer Modulation in a Dynamic Foldaxane: Proof-of-Principle of a LifetimeBased Conformation Probe. Angewandte Chemie International Edition, 2016, 55 (4), pp.1328-1333. 10.1002/anie.201508611. hal-01284111

\section{HAL Id: hal-01284111 \\ https://hal.science/hal-01284111}

Submitted on 20 Feb 2018

HAL is a multi-disciplinary open access archive for the deposit and dissemination of scientific research documents, whether they are published or not. The documents may come from teaching and research institutions in France or abroad, or from public or private research centers.
L'archive ouverte pluridisciplinaire HAL, est destinée au dépôt et à la diffusion de documents scientifiques de niveau recherche, publiés ou non, émanant des établissements d'enseignement et de recherche français ou étrangers, des laboratoires publics ou privés.

\section{다(1)(2)}

Distributed under a Creative Commons Attribution - ShareAlikel 4.0 International 


\title{
Electronic Energy Transfer Modulation in a Dynamic Foldaxane: Proof-of-Principle of a Lifetime-Based Conformation Probe
}

\author{
Sergey A. Denisov, Quan Gan, Xiang Wang, Luca Scarpantonio, Yann Ferrand,* \\ Brice Kauffmann, Gediminas Jonusauskas, Ivan Huc, and Nathan D. McClenaghan*
}

\begin{abstract}
Abiotic aromatic oligoamide foldamers are shown to self assemble in solution to form a double helix, which can accommodate a bichromophoric thread in its central void. While in solution reversible electronic energy transfer is instilled between chromophoric termini of the free, flexible thread as evidenced through delayed luminescence, upon rigidification of the rod the chromophores are mutually distanced and effectively decoupled. Consequently, the chro mophores display their individual photophysical character istics. The observed conformation dependent changes of dynamic luminescence properties, which are particularly sensitive to distance, offers a new strategy for lifetime based detection of geometry on the molecular scale as demonstrated through real time luminescence detection of molecular com plexation leading to foldaxane formation.
\end{abstract}

$T_{\text {he study of dynamic supramolecular architectures, includ }}$ ing stimulus responsive systems, mimicking structural and mechanical properties of large biomolecules and assemblies is a growing research area. In this regard, a range of foldamer based architectures ${ }^{[1]}$ have been reported, including helical containers, ${ }^{[2]}$ proton $^{[3]}$ or light induced folding, ${ }^{[4]}$ chiroptical switches, ${ }^{[5]}$ and metal/ion responsive systems. ${ }^{[6]}$ Most recently, interpenetration of a synthetic aromatic oligoamide helix by a linear dumbbell thread has been demonstrated, giving rise to dynamic pseudorotaxane structures termed foldaxanes. ${ }^{[7]}$ Herein we report photoactive foldaxane prototypes and the

[*] Dr. S. A. Denisov, Dr. L. Scarpantonio, Dr. N. D. McClenaghan Univ. Bordeaux CNRS UMR 5255

351 Crs de la Libération, 33405 Talence (France)

E mail: nathan.mcclenaghan@u bordeaux.fr

Q. Gan, X. Wang, Dr. Y. Ferrand, Dr. I. Huc

Université de Bordeaux, CBMN, UMR5248, Institut Européen de Chimie et Biologie

2 rue Escarpit, 33600 Pessac (France)

and

CNRS, CBMN, UMR5248 (France)

E mail: y.ferrand@iecb.u bordeaux.fr

Dr. S. A. Denisov, Dr. G. Jonusauskas

Univ. Bordeaux CNRS UMR 5798

351 Crs de la Libération, 33405 Talence (France)

Dr. B. Kauffmann

Université de Bordeaux, UMS3033, Institut Européen de Chimie et Biologie (IECB)

2 rue Escarpit, 33600 Pessac (France)

and

CNRS, IECB, UMS3033 INSERM, IECB, US001 (France) application of reversible electronic energy transfer (REET), and resulting luminescence lifetime increase (see below), as a new method to probe conformational changes/distances, in this case accompanying the unfolding refolding of a double helical synthetic aromatic oligoamide ${ }^{[8]}$ foldamer around a dumbbell shaped bichromophoric rod (Figure 1a). The

a)

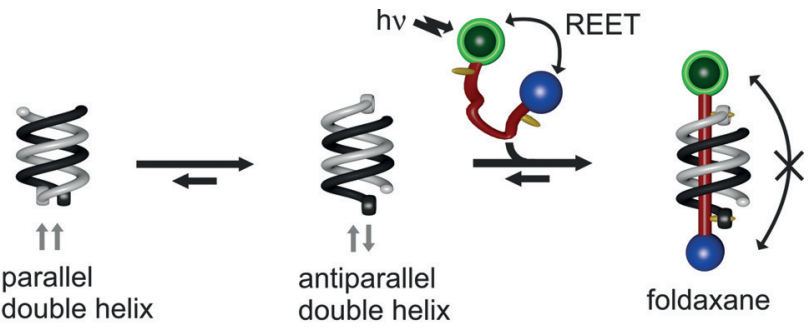

b)
$k_{E T}=\frac{2 \pi}{h} K J \exp \left(\frac{-2 r}{L}\right)$
eq. 1
$\tau=\left[\frac{\alpha}{\tau_{M L C T}}+\frac{1-\alpha}{\tau_{\text {pyrene }}}\right]^{-1}$
eq. 2

c)

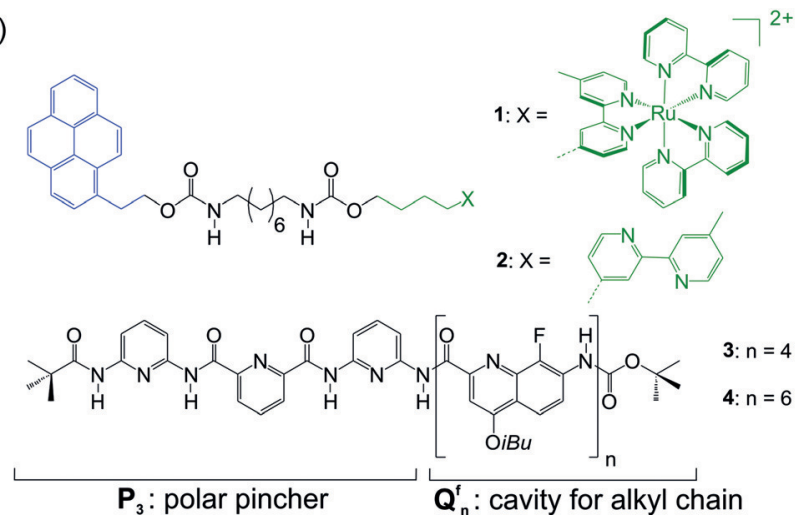

Figure 1. a) Representation of the parallel antiparallel equilibrium of a double helix and the assembly modulated photophysical properties. b) Equations describing Dexter type electronic energy transfer (eq. 1) and the observed luminescence lifetime when REET is operational (eq. 2). c) Structural formula of bichromophoric rod 1, its precursor 2, and the aromatic oligoamide sequences 3 and 4 . Hexafluorophosphate counter anions are omitted in $\mathbf{1}$ for clarity.

bulky chromophoric units at each extremity of the guest are too large to go through the helix central cavity, implying that the complex cannot form by a fast threading mechanism but through a slower helix winding around the guest. ${ }^{[7 b]}$ In the final complex, the distance between terminal chromophoric units is fixed by the long rigid helix, which forms a sheath 
around the alkyl chain, thus altering REET between them. REET gives rise to excited state lifetime elongation resulting from short range bidirectional triplet triplet energy transfer/ shuttling, and as such is fundamentally different from popular Förster resonance energy transfer (FRET), which is unidirec tional. Indeed the current approach is much more sensitive to distance $r$ at the nanometer or subnanometer scale, as it relies on a Dexter rather than a Förster energy transfer mechanism (Figure $1 \mathrm{~b}$, eq. 1 , where $J$ is the integral overlap between the normalized donor emission and acceptor absorption spectra, $L$ is the effective average Bohr radius of the excited and unexcited states of the donor and acceptor $(0.76 \AA$, with an average value of $1.5 \AA^{[9]}$ ), and $K$ is the experimental factor). Additionally, resulting long luminescence lifetimes equally offer the possibility of time gated detection, which is not hampered by background fluorescence and higher photon densities can also be obtained with respect to lanthanide complexes. $^{[10]}$

REET can be instilled in bichromophoric molecular systems when specific energetic and kinetic conditions are respected, but examples are relatively few. $\left.{ }^{[11} 13\right]$ Photoactive thread 1 (Figure $1 \mathrm{c}$ ) comprises an inorganic $\mathrm{Ru}(\mathrm{bpy})_{3}{ }^{2+}$ like chromophore (bpy $=2,2^{\prime}$ bipyridine), whose emissive ${ }^{3}$ MLCT state is quasi isoenergetic ${ }^{[12]}$ with an organic triplet on a pyrene $\left({ }^{3} \mathrm{Pyr}\right)$ unit that is located at the opposite terminus of a long and flexible saturated molecular thread. This energy similarity allows energy to shuttle back and forth between the two chromophores (Supporting Information, Figure S13) when they can approach one another. Considering that deexcitation of an organic triplet is slower than that of a ${ }^{3}$ MLCT state, and at short distances intercomponent energy transfer is more rapid, the system can reach an excited state equilibrium and emission would emanate predominantly from the inorganic center, with pyrene acting as an energy storage reservoir. ${ }^{[12]}$ Thus it would be anticipated that a longer luminescence lifetime would be obtained in the free thread (according to eq. 2), while conformation juxtaposition of the helical host on the flexible thread would decouple the chromophores and emission lifetime would decrease. In the absence of additional quenching mechanisms, this decrease of emission lifetime should not be accompanied by a change in quantum yield. It is noteworthy that the approach to signal interchromophore distance, introduced herein, may be applied to any matched chromophore pair, allowing variation of timescales and colors, adding to the versatility of the approach. $^{[13]}$

Considering the free bichromophoric rod 1, whose syn thesis is detailed in the Supporting Information, the electronic absorption spectrum (Figure S8) shows the distinct additive contributions of the pyrene and ruthenium based chromo phores, showing that the long insulating bridge electronically isolates the chromophores. Characteristic red emission $\left(\lambda_{\max }=\right.$ $620 \mathrm{~nm}$ ) is observed irrespective of excitation wavelength as excitation energy is ultimately efficiently funneled to the emissive ruthenium moiety. However, enhanced oxygen sensitivity is observed $\left(\Phi_{\text {deoxy }} / \Phi_{\text {oxy }}=9.6\right)$ with respect to the parent chromophore, which is diagnostic of an enhanced triplet lifetime that was confirmed through analysis of time resolved luminescence decays. Indeed, while parent $\mathrm{Ru}$
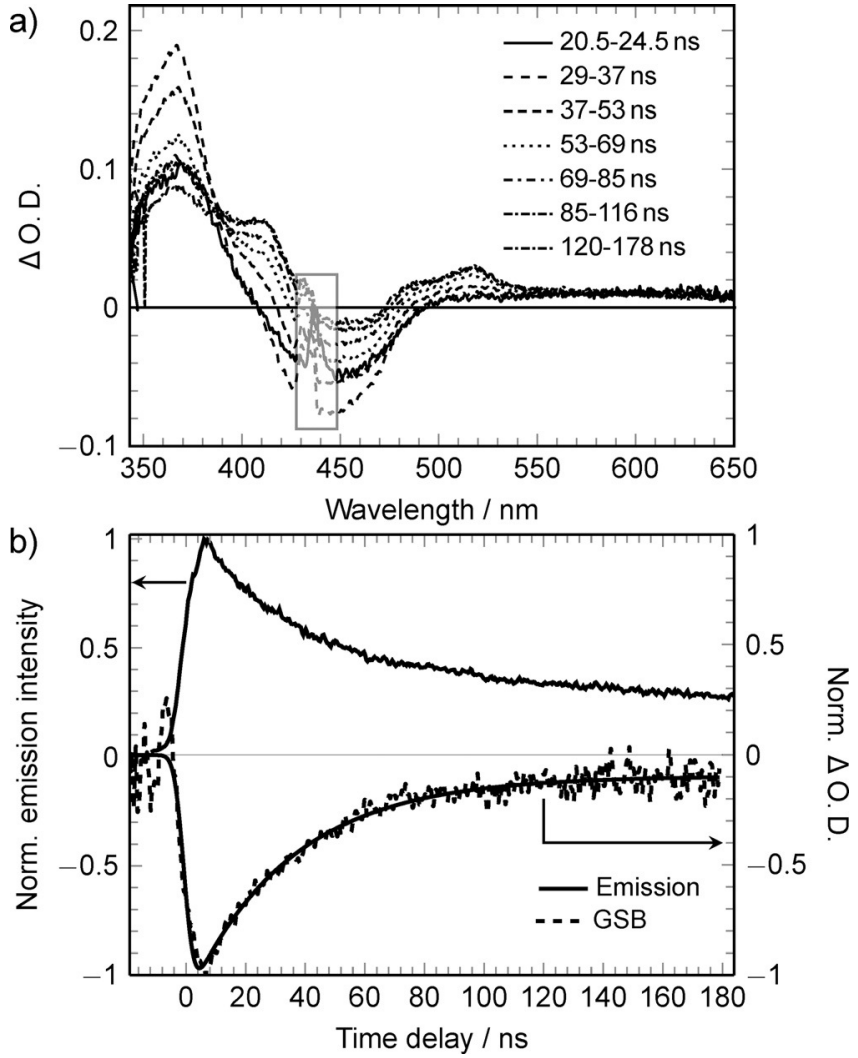

Figure 2. a) Transient absorption spectra of 1 in $\mathrm{CDCl}_{3}\left(\lambda_{\text {exc }} 440 \mathrm{~nm}\right)$ at varying time domains. The gray box corresponds to excitation diffusion. b) Time resolved emission decay of 1 in $\mathrm{CDCl}_{3}\left(\lambda_{\text {ex }} 465 \mathrm{~nm}\right.$, $\lambda_{\text {obs }} 620 \mathrm{~nm}$ ) and ground state bleaching (GSB, $\lambda_{\text {obs }} 450460 \mathrm{~nm}$ ) recovery of excited 1 .

(bpy) ${ }_{3}{ }^{2+}$ is characterized by a sub microsecond monoexpo nential decay in degassed $\mathrm{CHCl}_{3}$ (ca. $700 \mathrm{~ns}$ ), the situation is different for bichromophore $\mathbf{1}$, where a biexponential decay is observed ( $\tau=28 \mathrm{~ns}, 20 \%$ and $2.5 \mu \mathrm{s}, 80 \%$ : Figure $2 \mathrm{~b}$ ). This behavior can be rationalized by considering a dynamic excited state equilibrium involving both chromophores, where the short component corresponds to the time required for energy to be redistributed between the chromophores to attain an excited state equilibrium (at a rate $k_{\text {eq }}=1 / \tau=3.5 \times$ $10^{7} \mathrm{~s}^{-1}$ ) and the microsecond decay corresponds to the deexcitation of the equilibrated excited states. The relatively slow approach to equilibrium for $\mathbf{1}$, compared to sub ns processes in bichromophoric species with shorter linkers, ${ }^{[12,13]}$ may be explained by the fact that the $\mathrm{Ru}^{\mathrm{II}}$ center of the thread is attached to a pyrene energy reservoir through a long chain, requiring reorganization to allow the transfer to occur, consequently slowing it down. Owing to Brownian motion and bond rotation, the distance between the inorganic $\left(\mathrm{Ru}^{2+}\right)$ core and pyrene is constantly changing. The distribution of distances between the $\mathrm{Ru}$ core and pyrene is described by a Gaussian function centered at $1.0 \mathrm{~nm}$ with FWHM of $0.5 \mathrm{~nm}$, using the method described by Lakowicz (see the Supporting Information, Figure S14)..$^{[14]}$

In the dynamic equilibrated excited state, energy shuttles forwards and backwards between the ${ }^{3}$ MLCT state to the ${ }^{3} \mathrm{Pyr}$, and the observed long luminescence lifetime component 
is a weighted average of kinetic deexcitation parameters according to the distribution of excitation energy between the two chromophores (Figure 1b, eq. 2, where $\alpha$ corresponds to the fraction of populated ruthenium like triplets and $1 \alpha$ corresponds to the fraction of pyrene like triplets). Time resolved transient absorption spectroscopy was conducted to evidence the REET process and evaluate energy distribution (see the Supporting Information). Synchronous changes in absorption of a transient signal in the visible spectral region (namely ground state bleaching, GSB, recovery) and time resolved emission decay are shown in Figure 2. From analysis of the initial recovery of GSB to a metastable state, an equilibrium constant of $K_{\text {eq }}=5 \pm 1$ could be obtained (see the Supporting Information). From this $K_{\text {eq }}$ value the proportion of energy stored on ${ }^{3} \mathrm{MLCT}$ and ${ }^{3} \mathrm{Pyr}$ states at a given moment, was estimated at $16 \%(\alpha)$ and $84 \%\left(\begin{array}{ll}1 & \alpha\end{array}\right)$, respectively. The rate of backwards ( ${ }^{3} \mathrm{Pyr}$ to $\left.{ }^{3} \mathrm{MLCT}\right)$ energy transfer $k_{\mathrm{b}}=$ $k_{\text {eq }}\left(K_{\text {eq }}+1\right)=6.0 \times 10^{6} \mathrm{~s}^{-1}$, while forward $\left({ }^{3} \mathrm{MLCT}\right.$ to $\left.{ }^{3} \mathrm{Pyr}\right)$ energy transfer rate $k_{\mathrm{f}}=k_{\mathrm{eq}} k_{\mathrm{b}}=3.6 \times 10^{7} \mathrm{~s}^{-1}$.

To assess the winding of a foldamer around the bichro mophoric dumbbell guest, the new aromatic oligoamide sequence 4 was prepared. Previously, aromatic oligoamide sequence $\mathbf{3}$ was shown to self assemble as an antiparallel double helix which can form a foldaxane upon unfolding and refolding around dumbbell guests. ${ }^{[7 c]}$ Oligomer 4 was obtained by elongation of the $\mathbf{Q}^{\mathbf{F}}$ (7 amino 8 fluoro 2 quino linecarboxylic acid) segment of $\mathbf{3}$ (Figure 1c), which after Boc deprotection was coupled with the acid chloride of a $\mathbf{Q}^{\mathbf{F}}{ }_{2}$ dimer (Supporting Information, Scheme S2). Elongated strand 4 was likewise shown to form parallel and antiparallel $(4)_{2}$ duplexes but with enhanced stabilities compared to $(3)_{2}$ (Figure $3 \mathrm{a}$ ). Decreasing the concentration of 4 in $\mathrm{CDCl}_{3}$ from $0.5 \mathrm{~mm}$ to $0.125 \mathrm{~mm}$ caused some duplex dissociation (Sup porting Information, Figure S3). Integration of the ${ }^{1} \mathrm{H}$ NMR signals of the single versus the double helices allowed calculation of a dimerization constant $\left(K_{\mathrm{dim}}\right)$ of $5.9 \times$ $10^{4} \mathrm{~L} \mathrm{~mol}^{-1}$ at $298 \mathrm{~K}$ (Supporting Information, Figure S3), a value permitting titrations at $4 \mathrm{~mm}$ with a proportion of $(\mathbf{4})_{2}$ higher than $95 \%$. The double helical nature of $(\mathbf{4})_{2}$ was also evidenced in the solid state by X ray crystallography (Fig ure $3 d)$.

Foldaxane formation was first assessed using ${ }^{1} \mathrm{H}$ NMR titrations. Upon adding rod $\mathbf{1}$ to a solution of $(\mathbf{4})_{2}$, the signals corresponding to the parallel and antiparallel dimers were progressively replaced by a new single set of peaks corre sponding to $\mathbf{1} \subset(\mathbf{4})_{2}$ (Figure 3 a c). After 24 hours, the reso nances in the ${ }^{1} \mathrm{H}$ NMR spectra were unchanging and specific shifts in $\mathrm{NH}$ amide resonances could be assigned to hydrogen bond interactions between the two carbamate groups of the rod and the double helix. At thermodynamic equilibrium the association constant $\left(K_{\text {ass }}\right)$ was found to be $1700 \mathrm{Lmol}^{-1}$. Additionally, crystallographic evidence was sought to unam biguously show the interpenetrated nature of $\mathbf{1} \subset(\mathbf{4})_{2}$. While single crystals of suitable quality of the 1:1 host guest complex could not be grown, undoubtedly hampered by the presence of $\Lambda$ and $\Delta$ stereoisomers of the ruthenium moiety as well as the $P$ and $M$ isomers of the helix, single crystals of the analogous complex $\mathbf{2} \subset(\mathbf{4})_{2}$ were successfully obtained. ${ }^{[15,16]}$ As shown in Figure $3 \mathrm{e}$ and $3 \mathrm{f}$, the antiparallel double helix
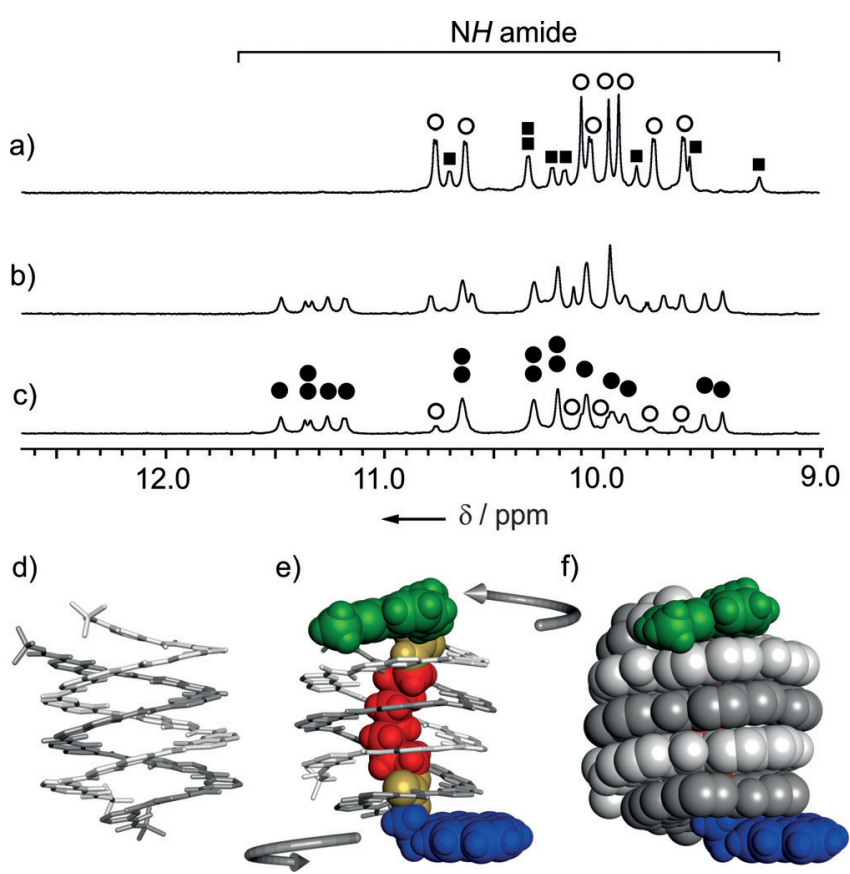

f)

Figure 3. Partial ${ }^{1} \mathrm{H}$ NMR spectra $(300 \mathrm{MHz}, 298 \mathrm{~K})$ showing the amide region of $(4)_{2}(2 \mathrm{~mm})$ in $\mathrm{CDCl}_{3}$ : a) in the absence of guest, b), c) in the presence of 1 b) 0.5 equiv and c) 2 equiv guest. The signals of the empty parallel and antiparallel double helix $(4)_{2}$ are marked with $\bigcirc$ and $\square$, respectively. The signals of $1 \subset(4)_{2}$ are denoted with •. d) f) Solid state structures ${ }^{[16]}$ of d) the free antiparallel double helix $\left.\left.(4)_{2}, e\right), f\right)$ the foldaxane $2 \subset(4)_{2}$. The antiparallel strands of $(4)_{2}$ are shown in gray and white tube $(d, e)$ and CPK $(f)$ representations. The rod like guest $\mathbf{2}$ is shown in CPK representation. The bipyridine and the pyrene stoppers are shown in green and blue, respectively. The carbamate functions and the linear alkyl chain of the guest are shown in gold and red, respectively. The gray arrows illustrate the unscrewing motion of $(4)_{2}$ to accommodate the guest. ${ }^{[7 c]}$

envelops the alkyl segment of the rod, thereby distancing the opposite terminus of sequestered $\mathbf{1}$ with the presence of bifurcated hydrogen bonds between the $\mathrm{NH}$ of the pyridine trimer $\left(\mathbf{P}_{3}\right)$ at each extremity of the double helix and the two carbonyl oxygen atoms of the $\operatorname{rod}\left(d_{\mathrm{NH} \cdots \mathrm{OC}} \approx 2.95 \AA\right)$. Impor tantly, the $\mathrm{X}$ ray structure allows interchromophore distances to be estimated at $\geq 1.8 \mathrm{~nm}$. This is noteworthy as it is generally considered that triplet triplet energy transfer, which depends on distance according to eq. 1 is inefficient beyond $1 \mathrm{~nm}$, which would mean the REET process would no longer be operational in the host guest complex. Conse quently, a shortening of the luminescence lifetime with respect to the free thread would be anticipated. Figure 4 shows the luminescence decays of both the dilute free thread $\mathbf{1}$ and a mixture of $\mathbf{1}$ and (4) $)_{2}$ (1:32, respectively; 2 mM of $\left.(\mathbf{4})_{2}\right)$, slowly leading to $77.5 \%$ formation of complex $\mathbf{1} \subset(\mathbf{4})_{2}$ in solution as demonstrated by ${ }^{1} \mathrm{H}$ NMR (see above). A luminescence lifetime of $1.2 \mu \mathrm{s}$ is thus obtained, half that of the free thread allowing discrimination of free and bound species.

The rate of the complexation process between $\mathbf{1}$ and (4), resulting in formation of $\mathbf{1} \subset(\mathbf{4})_{2}$ was studied using time resolved emission spectroscopy, on observing changes in the 


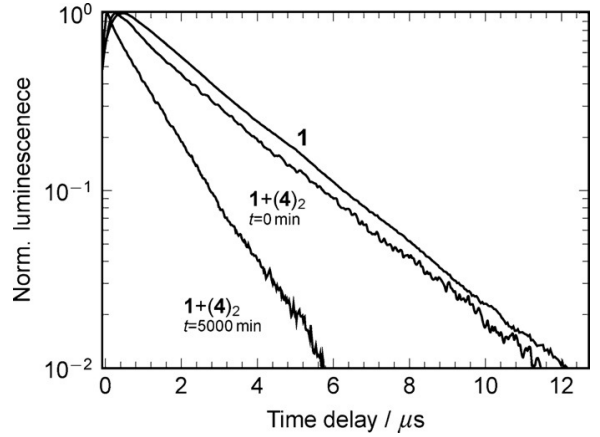

Figure 4. Luminescence decays on the microsecond timescale of free thread $1(50 \mu \mathrm{M})$ and host guest mixture (32:1, $2 \mathrm{~mm}$ of host) immediately after mixing ( $t \quad 0 \mathrm{~min}$ ) and at $t 5000 \mathrm{~min}$, when $77.5 \%$ formation of complex $1 \subset(4)_{2}$ is attained $\left(\lambda_{\text {ex }} \quad 465 \mathrm{~nm}, \lambda_{\text {obs }} 620 \mathrm{~nm}\right)$ in $\mathrm{CDCl}_{3}$.

${ }^{3}$ MLCT emission lifetimes $\left(\lambda_{\mathrm{ex}}=460 \mathrm{~nm}\right)$ with a streak camera. We studied different molar ratios of $\mathbf{1}$ and dimer $(4)_{2}$, namely: 1:6, 1:12, 1:32, on mixing degassed solutions in blowtorch sealed cells. The concentration of the host dimer was fixed at $2 \mathrm{~mm}$.

The data analysis merits consideration. During the com plexation experiments there are different emissive species in solution, principally free $\mathbf{1}$ and the $\mathbf{1} \subset(\mathbf{4})_{2}$ complex, which could be at different stages of binding between $\mathbf{1}$ and $(\mathbf{4})_{2}$. Concerning free $\mathbf{1}$, its emission lifetime is fixed and is about $2.5 \mu$ in degassed $\mathrm{CDCl}_{3}$, depending on concentration, while the lifetime of bound $\mathbf{1}$ is anticipated to have an unknown distribution which can complicate data treatment of such systems. As the primary goal in these experiments was to directly observe the effect of complexation on the rod elongation process and determine the rate of formation of $\mathbf{1} \subset(\mathbf{4})_{2}$, this was fulfilled by establishing the fraction of bound 1, tracked using emission lifetime dependence versus post mixing time in the complexation experiment. Rather than using distributions for emission lifetime of bound $\mathbf{1}$, emission decays were treated using a sum of two exponents $A \exp (t)$ $\left.\tau_{\text {short }}\right)+B \exp \left(t / \tau_{\text {long }}\right)$, where $\tau_{\text {long }}$ stands for lifetime of unbound $\mathbf{1}$ and $\tau_{\text {short }}$ for the $\mathbf{1} \subset(\mathbf{4})_{2}$ complex. This allows direct observation of the growth of the fraction of $\mathbf{1} \subset(\mathbf{4})_{2}$ during the experiment. A similar trend was obtained if the emission decay is fitted using one exponent (Supporting Information, Figure S11). Indeed, tail fitting of luminescence decays is often employed for facility of imaging longer components in complex mixtures. During the complexation process, as the fraction of $\mathbf{1} \subset(\mathbf{4})_{2}$ grows, the rate of emission increases, so by treating emission decays with one exponent, a general trend could be observed in the obtained dependency $\tau=f(\mathrm{t})$, allowing to ascertain whether the complexation process has several characteristic time constants or only one and determine values for them.

Figure 5 illustrates luminescence lifetime dependence as a function of time during the complexation process leading to $\mathbf{1 \subset}(\mathbf{4})_{2}$ as an averaged value $\tau=\left(A \cdot \tau_{\text {short }}+B \cdot \tau_{\text {long }}\right) /(A+B)$, where $\tau_{\text {long }}$ was fixed during the fitting procedure. The changes of fraction of $\tau_{\text {long }}$ during the experiment represent the decrease of the fraction of unbound $\mathbf{1}$. Figure 5 shows that

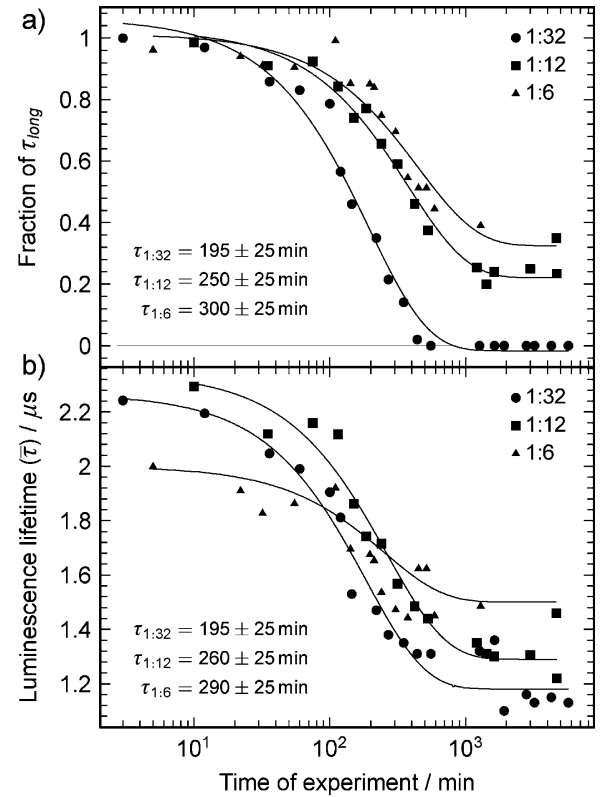

Figure 5. Real time complexation (time constant $\tau$ ) of 1 within (4) obtained by fitting a) temporal evolution of the fraction of long luminescence lifetime component and b) changes in observed average luminescence lifetime considering a biexponential decay.

the higher the relative concentration of $\mathbf{1}$, the longer the emission lifetime after the complexation process is com pleted. For the systems with thread:host ratios 1:32, 1:12, 1:6, the corresponding lifetime values of $1.1 \mu \mathrm{s}, 1.3 \mu \mathrm{s}$, and $1.5 \mu \mathrm{s}$ were obtained. As the binding constant for $\mathbf{1} \subset(\mathbf{4})_{2}$ equals $1700 \mathrm{M}^{-1}, 77.5 \%, 76 \%$, and $75 \%$ of $\mathbf{1}$ is bound in the $\mathbf{1} \subset(\mathbf{4})_{2}$ complex at stoichiometries 1:32, 1:16, and 1:6, respectively. Differences in lifetimes could be understood if the intermo lecular interactions between pyrene and $\mathrm{Ru}^{\mathrm{II}}$ center of differ ent 1 molecules were taken into account. At higher concen tration of $\mathbf{1}$ there are more possibilities for REET to occur between two different $\mathbf{1}$ molecules.

This interpretation could also explain the observation of such dependencies in fraction change of $\tau_{\text {long }}$ (Figure $5 \mathrm{~b}$ ). The time constant for foldaxane $\mathbf{1} \subset(\mathbf{4})_{2}$ formation $(\tau)$ at different ratios between $\mathbf{1}$ and (4) $)_{2}$ were determined by fitting the experimental curves (Figure 5) with a mono exponential function. The resulting values determined from changes in averaged luminescence lifetime $\tau$ and from fraction of the long lifetime of $\mathbf{1} \subset(\mathbf{4})_{2}$ are very similar and equal $\left(\tau_{1: 32}=195 \pm\right.$ $\left.25 \mathrm{~min}, \quad \tau_{1: 12}=250 \pm 25 \mathrm{~min}, \quad \tau_{1: 6}=290 \pm 50 \mathrm{~min}\right) .{ }^{1} \mathrm{H}$ NMR folding kinetic experiments were also carried out on solutions of $\mathbf{1 \subset ( 4 )})_{2}$ (Supporting Information, Figures S4 and S5) and proved to be in good agreement with luminescence lifetime measurements. Indeed, the folding of $(\mathbf{4})_{2}$ around $\mathbf{1}$ could be calculated to take place at a rate of $k=1.8 \mathrm{~min}^{-1} \mathrm{Lmol}^{-1}$. From this value a lifetime of $406 \mathrm{~min}$ at $2 \mathrm{~mm}\left([\mathbf{1}]_{\text {init }}=\left[(\mathbf{4})_{2}\right]_{\text {init }}\right)$ could be estimated, as $\tau=1 /\left(k\left[(\mathbf{4})_{2}\right]_{\text {init }} \cdot \ln 2\right)$.

Concerning mechanistic aspects of foldaxane winding, slow kinetics and solid state data (crystallographic structures of (4) $)_{2}$ and $\mathbf{2} \subset(\mathbf{4})_{2}$ show the cavity aperture to be smaller than the terminal chromophores of the thread) are consistent with an unfolding refolding mechanism of the helix around the 
dumbbell shaped rod. This would suggest partial (and stepwise) or alternatively complete double helix unzipping to accommodate the guest. As the luminescence lifetime is gradually shortening over the timeframe of the experiment to reach a fixed value, this is consistent with the progressive extension of the rod induced by the winding of the helix starting from one end, slowly advancing and ultimately expulsion of the lead chromophore from the opposite end of the host.

In conclusion, we demonstrated herein that a sensitive luminescence lifetime probe for distance or conformational change can be developed by exploiting the modulation of reversible electronic energy transfer processes. This was illustrated using a foldaxane architecture, the slow formation of which could be followed in real time. In principle the reported strategy should prove general for a wealth of energetically and kinetically matched chromophore pairs across a wide spectral and temporal window. Additionally, in the current case experiments were carried out in the submilli to micromolar concentration ranges, but more or less concentrated samples could be used depending on chromo phores used (inherent lifetimes, absorption, and emission quantum yield) and detection sensitivity, respectively. Indeed, qualitative and to a certain degree quantitative prediction of the photophysical properties may be possible using this strategy. These systems could, for example, potentially find use in studying a range of biological systems where nano metric conformational changes and/or rigidification accom panying interaction is present. Studies along these lines are currently in progress.

\section{Acknowledgements}

ANR project FOSET (contract no. ANR 12 BS08 0007 01), the Conseil Régional d'Aquitaine (predoctoral fellowship to Q.G.), European Research Council (FP7/2008 2013) grant agreement no. 208702, the University of Bordeaux (predoc toral fellowship to S.A.D.), and the China Scholarship Council (predoctoral fellowship to X.W.) are gratefully acknowledged for financial support.

Keywords: foldamers - molecular machines - photochemistry . reversible electronic energy transfer . ruthenium

[1] a) G. Guichard, I. Huc, Chem. Commun. 2011, 47, 5933; b) D. J. Hill, M. J. Mio, R. B. Prince, T. S. Hughes, J. S. Moore, Chem. Rev. 2001, 101, 3893; c) S. H. Gellman, Acc. Chem. Res. 1998, 31 , 173.

[2] G. Lautrette, C. Aube, Y. Ferrand, M. Pipelier, V. Blot, C. Thobie, B. Kauffmann, D. Dubreuil, I. Huc, Chem. Eur. J. 2014, 20,1547 .

[3] a) I. Okamoto, M. Nabeta, Y. Hayakawa, N. Morita, T. Takeya, H. Masu, I. Azumaya, O. Tamura, J. Am. Chem. Soc. 2007, 129 , 1892; b) C. Dolain, V. Maurizot, I. Huc, Angew. Chem. Int. Ed. 2003, 42, 2738; Angew. Chem. 2003, 115, 2844; c) E. Kolomiets, V. Berl, I. Odriozola, A. M. Stadler, N. Kyritsakas, J. M. Lehn, Chem. Commun. 2003, 2868.

[4] a) C. Tie, J. C. Gallucci, J. R. Parquette, J. Am. Chem. Soc. 2006, 128, 1162; b) Z. Yu, S. Hecht, Angew. Chem. Int. Ed. 2011, 50 1640; Angew. Chem. 2011, 123, 1678; c) Z. Yu, S. Hecht, Chem. Eur. J. 2012, 18, 10519.
[5] a) N. Chandramouli, Y. Ferrand, G. Lautrette, B. Kauffmann, C. D. Mackereth, M. Laguerre, D. Dubreuil, I. Huc, Nat. Chem. 2015, 7, 334; b) M. Peterca, M. R. Imam, C. H. Ahn, V. S. K. Balagurusamy, D. A. Wilson, B. M. Rosen, V. J. Percec, J. Am. Chem. Soc. 2011, 133, 2311; c) S. Akine, S. Hotate, T. J. Nabeshima, J. Am. Chem. Soc. 2011, 133, 13868; d) Y. Ferrand, A. M. Kendhale, B. Kauffmann, A. Grélard, C. Marie, V. Blot, M. Pipelier, D. Dubreuil, I. Huc, J. Am. Chem. Soc. 2010, 132, 7858; e) R. M. Meudtner, S. Hecht, Angew. Chem. Int. Ed. 2008, 47, 4926; Angew. Chem. 2008, 120, 5004; f) S. i. Sakurai, K. Okoshi, J. Kumaki, E. J. Yashima, J. Am. Chem. Soc. 2006, 128, 5650; g) K. Okoshi, S. i. Sakurai, S. Ohsawa, J. Kumaki, E. J. Yashima, Angew. Chem. Int. Ed. 2006, 45, 8173; Angew. Chem. 2006, $118,8353$.

[6] a) Y. Hua, Y. Liu, C. H. Chen, A. H. Flood, J. Am. Chem. Soc. 2013, 135, 14401; b) Y. Wang, F. Bie, H. Jiang, Org. Lett. 2010, 12, $3630 ;$ c) R. B. Prince, T. Okada, J. S. Moore, Angew. Chem. Int. Ed. 1999, 38, 233; Angew. Chem. 1999, 111, 245; d) M. Barboiu, J. M. Lehn, Proc. Natl. Acad. Sci. USA 2002, 99, 5201; e) A. M. Stadler, N. Kyritsakas, J. M. Lehn, Chem. Commun. 2004, 2024; f) H. Juwarker, J. M. Lenhardt, D. M. Pham, S. L. Craig, Angew. Chem. Int. Ed. 2008, 47, 3740; Angew. Chem. 2008, 120, 3800.

[7] a) Q. Gan, Y. Ferrand, N. Chandramouli, B. Kauffmann, C. Aube, D. Dubreuil, I. Huc, J. Am. Chem. Soc. 2012, 134, 15656; b) Q. Gan, Y. Ferrand, C. Bao, B. Kauffmann, A. Grélard, H. Jiang, I. Huc, Science 2011, 331, 1172; c) Y. Ferrand, Q. Gan, B. Kauffmann, H. Jiang, I. Huc, Angew. Chem. Int. Ed. 2011, 50, 7572; Angew. Chem. 2011, 123, 7714; d) A. Petitjean, H. Nierengarten, A. van Dorsselaer, J. M. Lehn, Angew. Chem. Int. Ed. 2004, 43, 3695; Angew. Chem. 2004, 116, 3781; e) A. Tanatani, M. J. Mio, J. S. Moore, J. Am. Chem. Soc. 2001, 123, 1792; f) A. Tanatani, T. S. Hughes, J. S. Moore, Angew. Chem. Int. Ed. 2002, 41, 325; Angew. Chem. 2002, 114, 335.

[8] For reviews, see: a) D. W. Zhang, X. Zhao, J. L. Hou, Z. T. Li, Chem. Rev. 2012, 112, 5271; b) I. Huc, Eur. J. Org. Chem. 2004, 17.

[9] a) M. Montalti, A. Credi, L. Prodi, M. T. Gandolfi, J. W. Grate, G. C. Frye, Handbook of Photochemistry, 3rd ed., CRC/Taylor \& Francis, London, 2006; b) M. Rae, A. Fedorov, M. N. Berberan Santos, J. Chem. Phys. 2003, 119, 2223.

[10] FRET generally considers nanosecond processes, but longer lived versions have been recently reported; see for example: $\mathrm{N}$. Hildebrandt, K. D. Wegner, W. R. Algar, Coord. Chem. Rev. 2014, $273274,125$.

[11] a) X. Y. Wang, A. Del Guerzo, R. H. Schmehl, J. Photochem. Photobiol. C 2004, 5, 55; b) A. Lavie Cambot, C. Lincheneau, M. Cantuel, Y. Leydet, N. D. McClenaghan, Chem. Soc. Rev. 2010, 39, 506; c) N. D. McClenaghan, Y. Leydet, B. Maubert, M. T. Indelli, S. Campagna, Coord. Chem. Rev. 2005, 249, 1336.

[12] a) W. E. Ford, M. A. J. Rodgers, J. Phys. Chem. 1992, 96, 2917; b) N. D. McClenaghan, F. Barigelletti, B. Maubert, S. Campagna, Chem. Commun. 2002, 602; c) D. S. Tyson, F. N. Castellano, J. Phys. Chem. A 1999, 103, 10955; d) M. Hissler, A. Harriman, A. Khatyr, R. Ziessel, Chem. Eur. J. 1999, 5, 3366; e) J. A. Simon, S. L. Curry, R. H. Schmehl, T. R. Schatz, P. Piotrowiak, X. Jin, R. P. Thummel, J. Am. Chem. Soc. 1997, 119, 11012.

[13] See for example: a) R. Passalacqua, F. Loiseau, S. Campagna, Y. Q. Fang, G. S. Hanan, Angew. Chem. Int. Ed. 2003, 42, 1608; Angew. Chem. 2003, 115, 1646; b) Y. Leydet, D. M. Bassani, G. Jonusauskas, N. D. McClenaghan, J. Am. Chem. Soc. 2007, 129, 8688 ; c) J. Peng, X. P. Jiang, X. Y. Guo, D. Zhao, Y. Ma, Chem. Commun. 2014, 50, 7828; d) M. B. Majewski, N. R. de Tacconi, F. M. MacDonnell, M. O. Wolf, Inorg. Chem. 2011, 50, 9939; e) S. M. Ji, W. H. Wu, W. T. Wu, H. M. Guo, J. Z. Zhao, Angew. Chem. Int. Ed. 2011, 50, 1626; Angew. Chem. 2011, 123, 1664; f) B. W. Cohen, B. M. Lovaasen, C. K. Simpson, S. D. Cummings, R. F. Dallinger,M.D.Hopkins, Inorg.Chem. 2010, 49,5777. 
[14] a) J. Lakowicz, Principles of Fluorescence Spectroscopy, Kluwer Academic/Plenum Publishers, N ew York, 1999; b ) A. F. Morales, G . A ccorsi, N. Armaroli, F. Barigelletti, S. J. A. Pope, M. D. Ward, Inorg. C hem. 2002, 41, 6711.

[15] A. von Zelewsky, Stereochemistry of Coordination Compounds, Wiley, New York, 1996.
[16] CCDC 1418615 for (4) $)_{2}$ and 1418616 for $\mathbf{2} \subset(\mathbf{4})_{2}$ contains the supplementary crystallographic data for this paper. These data can be obtained free of charge from The Cambridge Crystallographic Data Centre. 